\title{
Bipolar versus fixed-head hip arthroplasty for femoral neck fractures in elderly patients
}

\author{
Mostafa Abdelkhalek - Mohamed Abdelwahab • \\ Ayman M. Ali
}

Received: 29 July 2008/Accepted: 28 December 2010/Published online: 22 January 2011

(C) The Author(s) 2011. This article is published with open access at Springerlink.com

\begin{abstract}
Between 2002 and 2007, fifty elderly patients with displaced femoral neck fractures were treated with hip replacement at Emergency Hospital, Mansoura University. Patients were randomly selected, 25 patients had either cemented or cementless bipolar prosthesis, and another 25 patients had either cemented or cementless fixed-head prosthesis. There were 34 women and 16 men with an average age of 63.5 years (range between 55 and 72 years). All patients were followed up both clinically and radiologically for an average 4.4 years (range between 2 and 6 years). At the final follow-up, the average Harris hip score among the bipolar group was 92 points (range between 72 and 97 points), while the fixed-head group was 84 points (range between 65 and 95 points). Radiologically, joint space narrowing more than $2 \mathrm{~mm}$ was found in only $8 \%$ (2 patients) among the bipolar group, and in $28 \%$ (7 patients) of the fixed-head group. Through the follow-up period, total hip replacement was needed in two cases of the bipolar group and seven cases of the fixed-head group. Bipolar hemiarthroplasty offered a better range of movement with less pain and more stability than the fixed-head hemiarthroplasty in elderly patients with displaced femoral neck fractures.
\end{abstract}

Keywords Femoral neck fractures - Hip prosthesis . Arthroplasty

M. Abdelkhalek $(\bowtie) \cdot$ M. Abdelwahab · A. M. Ali

Department of Orthopedic Surgery, Mansoura University,

Dakahliya, Egypt

e-mail: aymanhusen2002@yahoo.com

\section{Introduction}

Since displaced intracapsular femoral neck fractures have a significant risk of nonunion and avascular necrosis, prosthetic replacement is often recommended in ambulatory, elderly patients [1]. The fixed-head hemiarthroplasty is associated with high acetablular erosion and protrusion rates, which affect the clinical results and makes revision to a total hip arthroplasty difficult [2].

These complications have led many surgeons to choose a bipolar design. The theoretical advantage of a bipolar hemiarthroplasty is to decrease acetabular erosion and wear and their associated symptoms [3]; however, there is still some debate concerning the benefits of bipolar versus the fixed-head hemiarthroplasty [4]. The aims of this study are to evaluate the results of bipolar versus fixed-head hemiarthroplasty for displaced femoral neck fractures in elderly patients and to address the problems of prosthesis selection.

\section{Patients and methods}

Fifty elderly patients with displaced femoral neck fractures were treated at Emergency Hospital, Mansoura University with hemiarthroplasty. There were 34 women and 16 men. The average age at operation was 63.5 years (range 55-72 years). Patients were allocated randomly, with alternate cases undergoing a bipolar or fixed-head hemiarthroplasty. Surgery was performed in all cases through the posterior approach of the hip. The method of prosthesis fixation (either cemented or cementless) was selected intraoperatively depending on the quality of bone and the presence or absence of a sufficient calcar of the femoral neck. Cement was introduced using a cement gun. In the bipolar group, 12 patients had a cemented prosthesis while 
Table 1 Types of prosthesis

\begin{tabular}{llr}
\hline Types & Number & $\%$ \\
\hline Cemented bipolar & 12 & 48 \\
Cementless bipolar & 13 & 52 \\
Austin Moore's prosthesis & 10 & 40 \\
Cemented Thompson & 15 & 60 \\
Total & 50 & 100 \\
\hline
\end{tabular}

13 patients had a cementless prosthesis. In the fixed-head group, 15 patients had a cemented Thompson prosthesis and 10 patients had a Austin Moore's prosthesis (Table 1).

All patients had prophylactic low molecular weight heparin $12 \mathrm{~h}$ pre-operatively and daily post-operatively for 5 days. Ambulation with weight bearing as tolerated was started on the second or third post-operative day.

All patients were followed up and evaluated clinically and radiologically post-operatively at 6 weeks, 3 months, 6 months, and at 1 year and then annually.

Clinically, hip function was evaluated using the Harris hip score with a total score of 100 points according to the presence or absence of pain, the use of support, the distance walked, the presence or absence of limp, activities, the manner of using stairs, public transportation, sitting, deformities, and the range of motion. In the Harris hip score, a total score above 90 points is an excellent result,

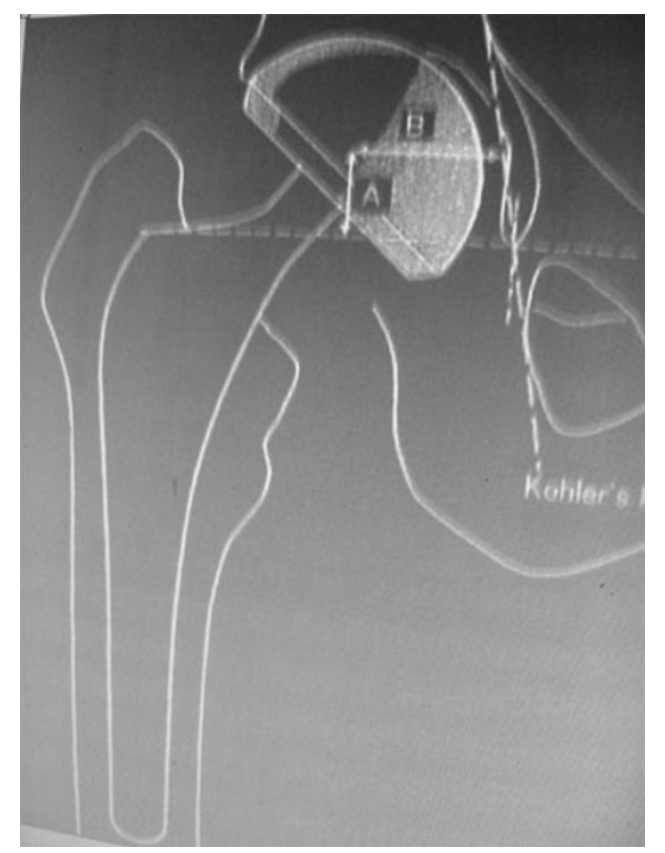

Fig. 1 Measurement of outer head migration (Murzic and McCollum) [5]. A Superior migration is assessed by measuring the distance between the center of the outer head and the inferior margin of the ipsilateral tear drop. $B$ Medial migration is determined by measuring the distance from Kohler's line and the center of the outer head
$80-90$ points is a good result, $70-80$ points is a fair result, and below 70 points is a poor result.

Radiological evaluation included antero-posterior and lateral views. Migration of the prosthesis in the acetabulum was defined by the method of Murzic and McCollum [5], which included medial migration and superior migration. Superior migration is assessed by measuring the distance between the center of the outer head and the inferior margin of the ipsilateral tear drop. Medial migration is determined by measuring the distance from Kohler's line and the center of the outer head (Fig. 1).

Acetabular cartilage erosion was determined by measuring the change in thickness of the acetabular cartilage compared with the immediate post-operative film. Femoral component subsidence was determined by comparing measurements from the prosthesis collar to the lesser trochanter as described by Gingras et al. [6]. Radiographic femoral loosening was recorded by measuring radiolucencies at the prosthesis-cement or cement-bone interface in the seven zones described by Gruen et al. [7].

\section{Results}

The duration of follow-up ranged between 2 and 6 years with an average of 4.4 years. The overall results showed a statistical significant favorable results for the bipolar group over the fixed-head group $(P=0.004)$. The average Harris hip score for the bipolar group was 92.3 points (range $72-97$ points) with $44 \%$ of cases had excellent results, $2 \%$ had good results, and $4 \%$ had fair results, while in the fixed hip group, the average Harris hip score was 84.3 points (range 65-95 points) with only $20 \%$ of cases had excellent results, $16 \%$ had good results, $10 \%$ had fair results, and $4 \%$ had poor results (Table 2).

Acetabular cartilage erosion and joint space narrowing was found in $14 \%$ of cases of fixed hip group and $4 \%$ of the bipolar group with a statistically significant difference $(P<0.05)$ (Table 3).

In the bipolar group, the superior and medial migrations in the acetabulum were $0-1.6 \mathrm{~mm}$ (average $0.5 \mathrm{~mm}$ ) and $0-1.0 \mathrm{~mm}$ (average $0.7 \mathrm{~mm}$ ), respectively. In the fixedhead group, they were $0-12 \mathrm{~mm}$ (average $3.4 \mathrm{~mm}$ ) and 0-8 $\mathrm{mm}$ (average $3.0 \mathrm{~mm}$ ), respectively. There was a statistical significance between both groups in the superior and medial migration $(P<0.05)$.

Calcar resorption (subsidence) was noted as early as 4 months post-operatively in three cases of Austin Moore prosthesis (Fig. 2). Two cases of acetabular protrusion occurred in the fixed-head group, while no case of protrusion in the bipolar group (Fig. 3).

There was a better range of movement in the bipolar group than the fixed-head group (Table 4). Limb length 
Table 2 Type of prosthetic replacement and Harris hip score

\begin{tabular}{|c|c|c|c|c|c|c|c|}
\hline & & \multicolumn{4}{|c|}{ Harris hip score } & \multirow[t]{2}{*}{$\chi^{2}$ test } & \multirow[t]{2}{*}{$P$ value } \\
\hline & & Excellent & Good & Fair & Poor & & \\
\hline \multirow[t]{2}{*}{ Types of prosthetic replacement } & Bipolar hemiarthroplasty $(n=25)$ & $22(44.0 \%)$ & $1(2.0 \%)$ & $2(4.0 \%)$ & $0(0.0 \%)$ & \multirow[t]{2}{*}{13.23} & \multirow[t]{2}{*}{0.004} \\
\hline & Fixed-head hemiarthroplasty $(n=25)$ & $10(20.0 \%)$ & $8(16.0 \%)$ & $5(10.0 \%)$ & $2(4.0 \%)$ & & \\
\hline
\end{tabular}

Table 3 Type of prosthetic replacement and joint space narrowing

\begin{tabular}{|c|c|c|c|c|c|}
\hline & & & \multicolumn{2}{|c|}{ Joint space narrowing $>2 \mathrm{~mm}$} & \multirow[t]{2}{*}{ Total } \\
\hline & & & Yes & No & \\
\hline \multirow[t]{4}{*}{ Types of prosthetic replacement } & Bipolar hemiarthroplasty & Count & 2 & 23 & 25 \\
\hline & & $\%$ of total & 4.0 & 46.0 & 50.0 \\
\hline & Fixed-head hemiarthroplasty & Count & 7 & 18 & 25 \\
\hline & & $\%$ of total & 14.0 & 36.0 & 50.0 \\
\hline \multirow[t]{2}{*}{ Total } & & Count & 9 & 41 & 50 \\
\hline & & $\%$ of total & 18.0 & 82.0 & 100.0 \\
\hline
\end{tabular}

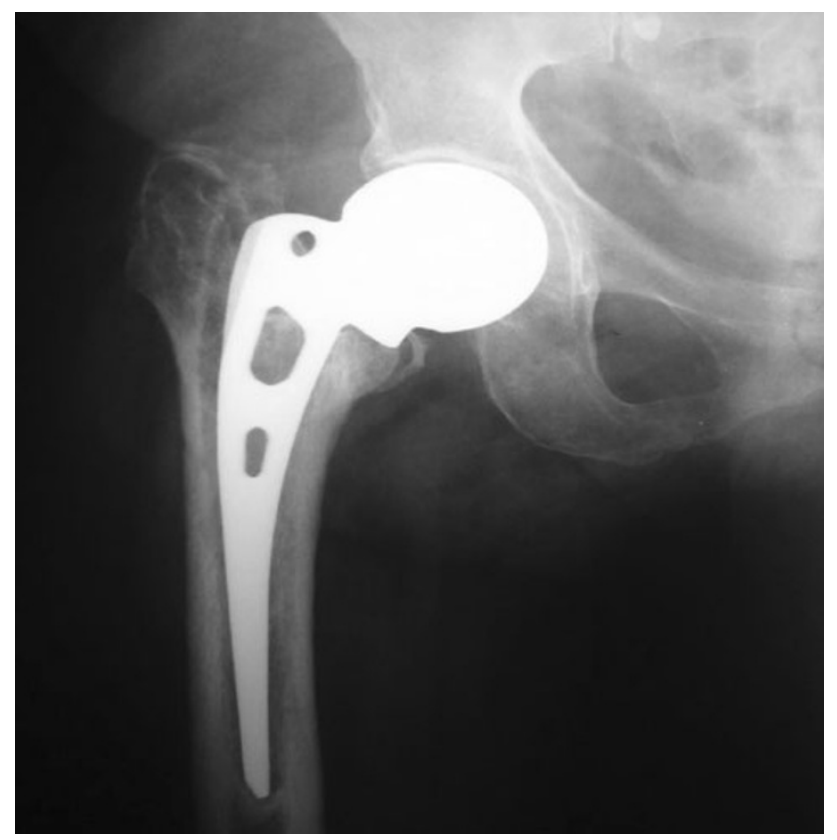

Fig. 2 A 64-year-old patient with fracture neck femur treated with Austin Moore arthroplasty. Two years post-operatively radiograph showed subsidence of the prosthesis

discrepancy less than $3.2 \mathrm{~cm}$ (1.5 inches) was found in one case $(2 \%)$ of bipolar group and six cases $(12 \%)$ with the fixed-head group. Through the follow-up period, total hip replacement was needed in two cases of the bipolar group and seven cases of the fixed-head group. The most common cause of failure leading to revision was aseptic femoral loosening.

As regards, hip pain, in the bipolar group hip pain was absent in $17(68 \%)$ patients, $6(24 \%)$ had slight pain

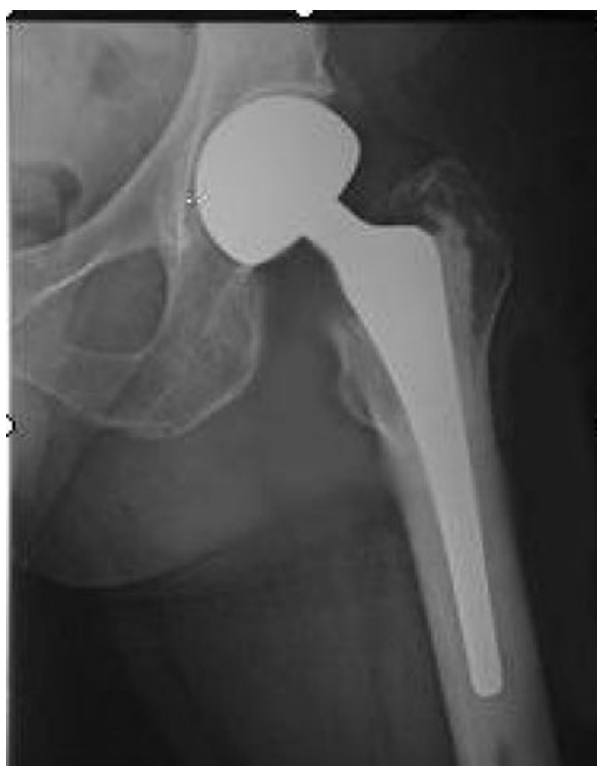

Fig. 3 A 67-year-old patient with fracture neck femur treated with bipolar hip arthroplasty. At the final follow-up radiograph showing the outer head of the prosthesis in the anatomic position, articular cartilage space has been preserved, and neither migration of the outer head nor loosening of the femoral stem was seen

Table 4 Range of motion

\begin{tabular}{llllll}
\hline & \multicolumn{2}{l}{ Bipolar [25] } & & \multicolumn{2}{l}{ Fixed-head [25] } \\
\cline { 2 - 3 } & Mean & SD & & Mean & SD \\
\hline Flexion & 94.68 & 2.39 & & 83.04 & 2.11 \\
Abduction & 15.52 & 0.65 & & 10.36 & 0.75 \\
Adduction & 14.04 & 0.67 & & 10.32 & 0.94 \\
External rotation & 13.96 & 0.73 & & 9.72 & 0.84 \\
\hline
\end{tabular}


Table 5 Hip pain in bipolar and fixed-head groups

\begin{tabular}{|c|c|c|c|c|c|c|}
\hline \multirow[t]{2}{*}{ Pain score } & \multicolumn{2}{|c|}{ Bipolar [25] } & \multicolumn{2}{|c|}{ Fixed-head [25] } & \multirow[t]{2}{*}{$\chi^{2}$} & \multirow[t]{2}{*}{$P$ value } \\
\hline & $N$ & $\%$ & $N$ & $\%$ & & \\
\hline Non & 17 & 68.0 & 7 & 28.0 & 8.452 & 0.038 \\
\hline Slight & 6 & 24.0 & 12 & 48.0 & & \\
\hline Mild to moderate & 2 & 8.0 & 5 & 20.0 & & \\
\hline Severe & 0 & 0.0 & 1 & 0.0 & & \\
\hline
\end{tabular}

Table 6 Hip pain in cemented and noncemented groups

\begin{tabular}{lrrrrrrr}
\hline Pain score & \multicolumn{2}{l}{ Cemented [22] } & & \multicolumn{2}{l}{ Noncemented [28] } & $\chi^{2}$ & $P$ value \\
\cline { 2 - 3 } & $N$ & $\%$ & & $N$ & $\%$ & & \\
\hline Non & 13 & 59.1 & & 11 & 39.3 & 2.627 & 0.453 \\
Slight & 6 & 27.3 & & 12 & 42.9 & & \\
Mild & 3 & 13.6 & & 4 & 14.3 & & \\
Severe & 0 & 0.0 & & 1 & 3.6 & & \\
\hline
\end{tabular}

occasionally, and 2 (8\%) patients had mild-to-moderate hip discomfort. In the fixed-head group, 7 patient (28\%) had no pain, 12 (48\%) had slight occasional pain, 5 patients (20\%) had moderate pain, and only 1 patient $(4 \%)$ had severe disabling pain (Table 5). When comparing hip pain in bipolar group versus fixed-head group, the bipolar group had less pain than fixed-head group with a statistically significant value $(P=0.038)$. Cemented group also had less pain than noncemented group with a statistically insignificant value $(P=0.453)$ (Table 6$)$.

In the bipolar group, $90 \%$ of the patients had no limping and $10 \%$ had a slight limping, while in the fixed-head group $22 \%$ of the patients had a moderate-to-sever limping.

There was only one early dislocation that occurred 2 weeks after surgery in a case of cemented Thompson prosthesis, which was treated by open reduction and revision to a total hip arthroplasty was done. The cause of dislocation in this case was excessive retroversion of the prosthesis. Heterotopic ossification was present in one case of bipolar group. Superficial wound infection was encountered in two cases (4\%), and both were treated with culture-based antibiotics and frequent dressing. There were no cases of deep infection or D.V.T.

Regarding activity of the patients, $90 \%$ of the patients with bipolar prosthesis returned to their pre-injury level of activity, in comparison with $70 \%$ in the fixed-head group with a statistically significance value $(P=0.04)$.

\section{Discussion}

A bipolar hemiarthroplasty design has been used for the treatment of femoral neck fractures for more than 30 years.
The proposed advantages of using the bipolar design rather than the conventional fixed-head designs for femoral neck fracture in elderly patients are still controversial $[8,9]$.

In a study of forty cases of Austin Moore replacement done for femoral neck fractures over an average follow-up period of 26 months, Jadhav et al. [10] reported a high incidence of early postoperative pain of noninfective origin, which correlates well with osteolysis. Shortening was seen in $75 \%$ cases ranging from 1 to $7 \mathrm{~cm}$. A limp was seen in 35 cases $(87.5 \%)$ due to pain, shortening, or abductor muscle weakness. Radiological evidence of complications like sinking, protrusion, and calcar resorption, etc. was seen in majority of the cases. In Andersson's series [11], only $6 \%$ cases walked without a limp. Sarmiento [12] in his post-mortems of 24 cases stated that there was "noticeable or excessive motion of stem in the canal and failure of cancellous bone to fill the entire fenestrations in the stem". Also, in his study of 160 Moore and Thompson prostheses, Whittaker et al. [13] reported that $5 \%$ of the acetabula had protrusion and $25 \%$ had narrowing after one to 4 years; $24 \%$ had protrusion and $64 \%$ had narrowing after more than 5 years. Gingras et al. [6] studied cemented Thompson endoprostheses for femoral neck fracture over an average follow-up period of 17 months. Ninety-two percent had no or slight pain, but $8 \%$ had evidence of protrusion. Wetherell and Hinves [14] reported a rate of erosion of $11 \%$ with the cemented Thompson prosthesis.

Efthekar [15] stated "pressure brought by the femoral prosthesis upon the acetabular cartilage makes subsequent migration of the prosthesis inevitable."

The bipolar prosthesis has two bearing surfaces; load and frictional torque can theoretically be absorbed in part by the metal on polyethylene inner bearing reducing the magnitude of forces between the implant and acetabulam thus decreasing acetabular erosion [16]. Drinker and Murray [17] in a retrospective series compared the bipolar prosthesis with the Thompson prosthesis and could not show a significant advantage to the bipolar prosthesis. Calder et al. [18] in his study concluded that there is no justification for the use of the expensive bipolar hip prosthesis in femoral neck fracture. On the other hand, La Belle et al. [19] reported that bipolar prosthesis resulted in less pain and decreased protrusio in comparison with the conventional fixed-head prosthesis. Lestrange [20] reviewed 496 patients with bipolar replacements for displaced femoral neck fractures and compared them with patients having fixed-head prosthesis. He found that the bipolar prosthesis offered advantages over one piece designs in terms of stability, decreased acetabular erosion, and improved function.

In the current study, at the final follow-up, the overall results showed better results that were statistically significant for the bipolar group over the fixed-head group in 
Harris hip scores, acetabular erosion and protrusion. Our results disagree with the randomized prospective study of Van Thiel et al. [21] and Calder et al. [18], who did not find any differences between the Moore unipolar and bipolar prostheses concerning acetabular erosion. Our results are consistent with Yamagata et al. [22] and D'Arcy and Devas [23] who found more erosion with unipolar prosthesis, and Wetherell and Hinves [14] who reported a rate of erosion of $5.6 \%$ with the bipolar implant compared with $11 \%$ for the cemented Thompson prosthesis. Whittaker et al. [13] reported $5 \%$ of the acetabula protrusion after 1-4 year follow-up with Moore and Thompson prostheses. It was demonstrated in our series a lower incidence of acetabular protrusion in bipolar group in comparison with the fixedhead prosthesis. Micheal et al. [16] reported that the bipolar prosthesis reduces the acetabular shear forces through the use of an outer free acetabular cup that also articulates with a prosthetic femoral head. Sikorski [24] reported dislocation rates of $10 \%$ in the Thompson prostheses. LaBelle [19] in his study of bipolar hip arthroplasty for femoral neck fractures reported incidence of $0.8 \%$ dislocation. In our study, there was no dislocation of prosthesis in the bipolar group, while the incidence of dislocation with fixed-head prosthesis was 4\%. This is consistent with Attarian et al. [25] who reported that bipolar prosthesis has a self-aligning acetabular component, which finds a correct orientation on its own (a self-centering mechanism), and the incidence of subluxation and dislocation is low.

The theoretical advantages of inner bearing motion of bipolar prosthesis have not been supported in the majority of the motion studies [1]. Verberne [26] reported that intraprosthetic motion was absent 3 months after surgery. Tsukamoto et al. [27] suggested that motion during walking occurred mainly at the outer bearing. Brueton et al. [28] showed that the size of the inner head was an important determination in allowing inner bearing motion. Small heads $(22 \mathrm{~mm})$ allowed bipolar motion, whereas large heads $(32 \mathrm{~mm})$ hindered inner bearing motion. The prostheses studied by Verberne [26] had a 32-mm head. Calder [18] reported that movement within the prosthesis may also reduce the pain caused by the prosthesis moving against the acetabulum. In our study, the bipolar group had a better range of motion and $90 \%$ of the patients had no limping and $10 \%$ had a slight limping, while in the fixed-head group, $22 \%$ of the patients had a moderate to severe limping. Favorable results of bipolar may be contributed by the fact that the modularity of the bipolar prosthesis allows for greater flexibility in "customizing" prosthetic sizing so that soft tissue tension and limb length equalization can be improved by ability to use variable neck lengths intraoperatively. This coincides with Cornell et al. [8] who reported that patients with bipolar prosthesis did better on walk tests and had better range of motion at 6 months.
From our results, the bipolar hemiarthroplasty seems to offer a better range of movement with less pain and more stability than the fixed-head hemiarthroplasty in elderly patients with displaced femoral neck fractures in spite of the increased cost factor.

Open Access This article is distributed under the terms of the Creative Commons Attribution License which permits any use, distribution and reproduction in any medium, provided the original author(s) and source are credited.

\section{References}

1. Phillips TW (1987) The Bateman bipolar femoral head replacement. J Bone Joint Surg 69B:761

2. Bowman AJ, Walker MW, Kilfoyle RM, O’Brien PI, McConville JF (1985) Experience with the bipolar prosthesis in hip arthroplasty. Orthopaedics 8:460

3. Lausten OS, Vedel P, Nielsen P-M (1987) Fractures of the femoral neck treated with a bipolar endoprosthesis. Clin Orthop 218:63

4. Long JW, Knight W (1980) Bateman prosthesis in fractures of the femoral neck. Clin Orthop 152:198

5. Murzic WJ, McCollum DE (1994) Hip arthroplasty for osteonecrosis after renal transplantation. Clin Orthop 299:212

6. Gingras MB, Clarke J, Evans CM (1980) Prosthetic replacement in femoral neck fractures. Clin Orthop 152:147

7. Gruen TA, McNeice GM, Amstutz HC (1979) "Modes of failure" of cemented stem-type femoral components: a radiographic analysis of loosening. Cin Orthop 141:17

8. Cornell CN, Levine D, O’Doherty J, Lyden J (1998) Unipolar versus bipolar hemiarthroplasty for the treatment of femoral neck fractures in the elderly. Clin Orthop Relat Res 348:67-71

9. Ong BC, Maurer SG, Aharonoff GB, Zuckerman JD, Koval KJ (2002) Unipolar versus bipolar hemiarthroplasty: functional outcome after femoral neck fracture at a minimum of thirty-six months of follow-up. J Orthop Trauma 16:317-322

10. Jadhav AP, Kulkarni SS, Vaidya SV, Divekar MM, Suralkar SP (1996) Results of Austin Moore replacement. J Postgrad Med 42(2):33-38

11. Anderson LD, Hamsa WR, Waring T (1964) Femoral head prosthesis. J Bone Joint Sarg 46A:223-240

12. Sarmiento A (1972) Austin Moore prosthesis in the arthritic hip. Clin Orthop 82:14

13. Whittaker RB, Schell HW, Chung SM (1972) Fifteen years experience with metallic endoprosthetic replacement for femoral neck fractures. J Trauma 12:799

14. Wetherell RG, Hinves BL (1990) The Hastings bipolar hemiarthroplasty for subcapital fractures of the femoral neck: a 10-year prospective study. J Bone Joint Surg [Br] 72-B:788-793

15. Efthekar NS (1973) Status of femoral head replacement in treating fracture of the femoral neck, Part II The prosthesis and the surgical procedure. Orthop Rev 2:6

16. Micheal D, Ries MD, Jorome D, Wiedel MD (2000) Bipolar hip arthorplasty for recurrent dislocation after total hip arthorplasty. Clin Orthop 278:121

17. Drinker H, Murray WR (1979) The universal proximal femoral endoprosthesis. Bone Joint Surg 61A:1167

18. Calder SJ, Anderson GH, Jagger C, Harper WM, Gregg PJ (1996) Unipolar or bipolar prosthesis for displaced intracapsular hip fracture in octogenarians a randomised prospective study. J Bone Joint Surg [Br] 78-B:391-394 
19. La Belle LW, Colwill JC, Swanson A (1990) Bipolar hip arthroplasty for femoral neck fractures. A five to ten year followup study. Clin Orthop Relat Res 251:20-25

20. Lestrange NR (1990) Bipolar arthroplasty for 496 hip fractures. Clin Orthop 251:7-19

21. Van Thiel PH, Snellen JP, Jansen WBJ, van de Slikke W (1988) Moore prosthesis versus bipolar Bateman prosthesis: a prospective randomised clinical study. J Bone Joint Surg [Br] 70-B:677

22. Yamagata M, Chao EY, Ilstrup DM (1987) Fixed-head and bipolar hip endoprostheses: a retrospective clinical and roentgenographic study. J Arthroplasty 2:327-341

23. D'Arcy J, Devas M (1976) Treatment of fractures of the femoral neck by replacement with the Thompson prosthesis. J Bone Joint Surg [Br] 58-B:279-286
24. Sikorski JM, Barrington R (1981) Internal fixation versus hemiarthroplasty for the displaced subcapital fracture of the femur: a prospective study. J Bone Joint Surg [Br] 63-B:357-361

25. Attarian DE (1999) Bipolar arthroplasty for recurrent total hip instability. J Southern Orthop Assoc 8(4):249-253

26. Verberne VHM (1983) A femoral head with a built-in joint. J Bone Joint Surg 65B:544-547

27. Tsukamoto Y, Mabuchi K, Futami T, Kubotera D (1992) Motion of the bipolar hip prosthesis components. Acta Orthop Scand 63:648-652

28. Brueton N, Craig JSJ, Hinves BL, Heatley FW (1993) Effect of femoral component head size on movement of the two-component hemiarthroplasty. Injury 24:231-235 